University of Wollongong

Research Online

Faculty of Science - Papers (Archive)

Faculty of Science, Medicine and Health

2012

\title{
A reply to the comments by Thomsen et al. on "Luminescence dating of K- feldspar from sediments: a protocol without anomalous fading correction"
}

Bo Li

University of Hong Kong, bli@uow.edu.au

Shenghua $\mathrm{Li}$

University of Hong Kong

Follow this and additional works at: https://ro.uow.edu.au/scipapers

Part of the Life Sciences Commons, Physical Sciences and Mathematics Commons, and the Social and Behavioral Sciences Commons

\section{Recommended Citation}

$\mathrm{Li}, \mathrm{Bo}$ and Li, Shenghua: A reply to the comments by Thomsen et al. on "Luminescence dating of Kfeldspar from sediments: a protocol without anomalous fading correction" 2012, 49-51.

https://ro.uow.edu.au/scipapers/4610 


\title{
A reply to the comments by Thomsen et al. on "Luminescence dating of $\mathrm{K}$ - feldspar from sediments: a protocol without anomalous fading correction"
}

\begin{abstract}
We are pleased that Thomsen et al. (2012) has tested our newly proposed multi-elevated-temperature post-IR IRSL (MET-pIRIR) procedure ( $\mathrm{Li}$ and $\mathrm{Li}, 2011$ ) using their own samples, which provides an independent test on the validity of this procedure. In their study, Thomsen et al. (2012) found that the METpIRIR procedure gave consistent results with the two-step post-IR IRSL (TS-pIRIR) procedure originally proposed by [Thomsen et al., 2008] and [Buylaert et al., 2009] and Thiel et al. (2010), indicating the validity of both methods for their samples investigated. Based on this observation, they argued that the MET-pIRIR procedure has no advantage over the TS-pIRIR procedure, in which a $290^{\circ} \mathrm{C}$ post-IR IRSL was applied after a $50^{\circ} \mathrm{C}$ IRSL measurement.
\end{abstract}

\section{Keywords}

sediments, feldspar, k, dating, luminescence, al, et, thomsen, comments, reply, correction, anomalous, fading, without, protocol, CAS

\section{Disciplines}

Life Sciences | Physical Sciences and Mathematics | Social and Behavioral Sciences

\section{Publication Details}

Li, B. \& Li, S. (2012). A reply to the comments by Thomsen et al. on "Luminescence dating of K-feldspar from sediments: a protocol without anomalous fading correction. Quaternary Geochronology, 8 49-51. 


\title{
A reply to the comments by Thomsen et al on "Luminescence dating of K-feldspar from sediments: a protocol without anomalous fading correction"
}

\author{
Bo Li and Sheng-Hua Li \\ Department of Earth Sciences, The University of Hong Kong, Pokfulam Road, Hong Kong, China
}

We are pleased that Thomsen et al. (2011) has tested our newly proposed multi-elevatedtemperature post-IR IRSL (MET-pIRIR) procedure (Li et al., 2011) using their own samples, which provides an independent test on the validity of this procedure. In their study, Thomsen et al. (2011) found that the MET-pIRIR procedure gave consistent results with the two-step post-IR IRSL (TS-pIRIR) procedure originally proposed by Thomsen et al. (2008), Buyleart et al. (2009) and Thiel et al. (2011), indicating the validity of both methods for their samples investigated. Based on this observation, they argued that the MET-pIRIR procedure has no advantage over the TS-pIRIR procedure, in which a $290^{\circ} \mathrm{C}$ post-IR IRSL was applied after a $50^{\circ} \mathrm{C}$ IRSL measurement.

However, it is to be noted that the samples investigated in their study are limited to those samples with relatively small natural dose $(<250 \mathrm{~Gy})$. Since the effect of anomalous fading is strongly dependent on the natural dose received ( $\mathrm{Li}$ and $\mathrm{Li}, 2008$ ), a small anomalous fading rate might not be so effective in age estimation for samples with small natural dose. It can cause significant age underestimation for old samples with large natural doses. Hence, it is not surprising that the MET-pIRIR procedure and TS-pIRIR procedure give similar results for these samples, because of the small anomalous fading rate found in the pIRIR signals in their natural dose range $(<250 \mathrm{~Gy})$.

In order to checking whether a procedure is able to reduce the effect of anomalous fading rate to a negligible level, this method should be tested using older samples with larger natural doses. In our original paper ( $\mathrm{Li}$ and $\mathrm{Li}, 2011$ ), only one sample, FJGW1, was used for comparing the MET-pIRIR method and the TS-pIRIR method, which is not conclusive. Here we have further studied 6 loess samples, covering a wider range of sedimentary ages and natural doses, from the Luochuan section in the Chinese Loess Plateau. These samples are selected for testing the validity of dating procedures because the chronology of loess from the Luochuan section has been well 
established (Ding et al., 2002) and independent age controls can be obtained based on their stratigraphic positions. A summary of the samples, sampling depth, expected ages and doses, dose rate is shown in Table 1.

In this study, three measurement procedures were conducted. The first is the MET-pIRIR procedure ( $\mathrm{Li}$ and $\mathrm{Li}, 2011$ ), in which the infrared stimulated luminescence (IRSL) signal were measured by progressively increasing the stimulation temperature from 50 to $300{ }^{\circ} \mathrm{C}$ in step of $50^{\circ} \mathrm{C}$ and used a preheat of $320^{\circ} \mathrm{C}$ for $60 \mathrm{~s}$. It is noted that the highest stimulation temperature used in this study was different from the $250^{\circ} \mathrm{C}$ in the original paper of $\mathrm{Li}$ and $\mathrm{Li}(2011)$. This is because we found that it is necessary to use a higher stimulation temperature in the MET-pIRIR procedure in order to obtain an age plateau for old loess samples. This point was discussed in detail in $\mathrm{Li}$ and $\mathrm{Li}$ (submitted). Here only the MET-pIRIR signals at $250{ }^{\circ} \mathrm{C}$ were used for comparison, which is comparable to the results obtained using the original procedures proposed by $\mathrm{Li}$ and $\mathrm{Li}$ (2011). The second procedure is exactly following that proposed by Thiel et al (2011), in which a post-IR measurement at $290{ }^{\circ} \mathrm{C}$ was conducted after the $50{ }^{\circ} \mathrm{C}$ IRSL measurement, named pIRIR $(50,290)$. The third procedure is similar to the second one, except that the prior IRSL measurement was conducted at $200^{\circ} \mathrm{C}$ instead of $50^{\circ} \mathrm{C}$. The pIRIR measurement was conducted at $290{ }^{\circ} \mathrm{C}$, called pIRIR $(200,290)$. The three procedures are compared in Table 2 .

The equivalent doses and expected doses, obtained from expected ages and dose rates, are compared in Fig. 1. For the youngest sample investigated, LC-096, the expected dose (273 Gy) are consistent with the measured equivalent doses obtained by all 3 procedures within $\pm 1 \sigma$ errors. For sample LC-120, of which the expected dose is $425 \mathrm{~Gy}$, the results of MET-pIRIR (250) and $\operatorname{pIRIR}(200,290)$ are consistent with the expected dose within $\pm 1 \sigma$ errors. The result of the pIRIR $(50,290)$ is slightly lower than the expected dose but still consistent with each other within $\pm 2 \sigma$ errors. For these two younger samples, our results is consistent with the founding of Thomsen et al (2011), in which no distinctive difference was observed between the MET-pIRIR (250) and pIRIR $(50,290)$ results. For older samples, the MET-pIRIR (250) gave consistent results with the expected doses up to $\sim 900 \mathrm{~Gy}$. However, the results obtained using the pIRIR(50, 290) signal starts to get underestimated for samples with expected dose larger than $\sim 500 \mathrm{~Gy}$. The larger doses are, the larger extents of underestimation are observed for the samples. It interesting to note that, by increasing the stimulation temperature in the prior IRSL measurement from 50 to $200{ }^{\circ} \mathrm{C}$, the underestimation in age disappeared for the TS-pIRIR procedure. The results from 
pIRIR $(200,290)$ are consistent with the expected doses for all samples except one, sample LC205.

The results shown in Fig. 1 can be explained using recent model proposed for feldspar IRSL. It has been suggested that a higher IRSL stimulation temperature may access to more stable (nonfading) trapped charges (Poolton et al., 2002; Li, 2010; Jain and Ankjærgaard, 2011). In a study of the relationship between IRSL decay curve shape and anomalous fading, $\mathrm{Li}$ (2010) showed that post-IR IRSL at elevated temperatures can access those easy-to-fade electron-hole pairs, which are not accessible by low temperature IRSL. It is indicated that a higher stimulation temperature used in the first IR stimulation will remove more easy-to-fade signals than stimulation at low temperature does. A similar conclusion was also reached by Jain and Ankjærgaard (2011), who suggested that IR stimulation at elevated temperature will swipe a larger volume of electron-hole pairs, which causes a preferential removal of spatially close electron-hole pairs corresponding to the easy-to-fade signals. Therefore, it is expected that a progressive increase of stimulation temperature used in MET-pIRIR protocol will progressively remove the easy-to-fade electronhole pairs, in a better way than a single IR stimulation at low temperature. The results that the pIRIR(50, 290) signals get underestimation at higher doses (Fig. 1) confirmed that a short IR bleaching in laboratory (up to several hundred seconds) at $50{ }^{\circ} \mathrm{C}$ cannot completely remove all of the charges in easy-to-fade traps. Further evidence was shown by the observation that the underestimation in pIRIR $_{290}$ disappeared by increasing the prior IRSL stimulation temperature from 50 to $200{ }^{\circ} \mathrm{C}$ (Fig. 1), indicating that a high-temperature IRSL can remove more easy-tofade signals than the low-temperature IRSL. However, the MET-pIRIR protocol still have the advantage over the TS-pIRIR procedure in checking whether a non-fading component has been achieved from the 'age plateau' in the age-temperature plot ( $\mathrm{Li}$ and $\mathrm{Li}, 2011)$.

In summary, based on our new results shown in Fig. 1, it is concluded that:

1) The pIRIR $(50,290)$ can give reliable results for those samples with relatively small natural doses, e.g. $<400 \mathrm{~Gy}$. This is consistent with the findings by Thomsen et al (2011). But underestimation might be resulted for older samples with larger natural doses $(>400$ Gy). This is consistent with the dose-dependent change of the anomalous fading rate in the pIRIR(50, 290) signals ( $\mathrm{Li}$ and $\mathrm{Li}, 2008)$.

2) The two-step pIRIR procedure has potential to achieve a real non-fading signal by increasing the stimulation temperature of the prior IRSL measurement. A temperature as high as $200{ }^{\circ} \mathrm{C}$ is necessary. 
3) The MET-pIRIR (250) signal has negligible anomalous fading rate for our samples, and they can give reliable results up to $\sim 900 \mathrm{~Gy}$. It has advantages in checking for the reliability of the dating results.

\section{Reference}

Buylaert, J.P., Murray, A.S., Thomsen, K.J., Jain, M., 2009. Testing the potential of an elevated temperature IRSL signal from K-feldspar. Radiation Measurements 44, 560-565.

Ding, Z.L., Derbyshire, E., Yang, S.L., Yu, Z.W., Xiong, S.F., Liu, T.S., 2002. Stacked 2.6-Ma grain size record from the Chinese loess based on five sections and correlation with the deep-sea D18O record. Paleoceanography 17, 1033.

Jain, M., Ankjærgaard, C., 2011. Towards a non-fading signal in feldspar: insight into charge transport and tunnelling from time-resolved optically stimulated luminescence. Radiation Measurements 46, 292-309.

Poolton, N.R.J., Ozanyan, K.B., Wallinga, J., Murray, A.S., Bøtter-Jensen, L., 2002a. Electrons in feldspar II: a consideration of the influence of conduction band-tail states on luminescence processes. Physics and Chemistry of Minerals 29, 217-225.

Li, B., 2010. The relationship between thermal activation energy, infrared stimulated luminescence and anomalous fading of K-feldspars. Radiation Measurements 45, 757763.

Li, B., Li, S.H., 2008. Investigations of the dose-dependent anomalous fading rate of feldspar from sediments. Journal of Physics D-Applied Physics 41, 225502.

Li, B., Li, S.H., 2011. Luminescence dating of K-feldspar from sediments: a protocol without anomalous fading correction. Quaternary Geochronology, doi:10.1016/j.quageo.2011.05.001

Li, B., Li, S.H., 2011. Luminescence dating of Chinese Loess beyond $130 \mathrm{ka}$ using the non-fading signal from K-feldspar. Quaternary Geochronology, submitted.

Thiel, C., Buylaert., J.P., Murray, A.S., Terhost. B., Hofer, I., Tsukamoto, S., Frechen, M., 2011. Luminescence dating of the Stratzing loess profile (Austria) - Testing the potential of an elevated temperature post-IR IRSL protocol (Accepted in Quaternary International).

Thomsen, K.J., Murray, A.S., Jain, M., Botter-Jensen, L., 2008. Laboratory fading rates of various luminescence signals from feldspar-rich sediment extracts. Radiation Measurements 43, 1474-1486. 
Thomsen, K.J., Murray, A.S., Jain, M., Buylaert, J.P., 2011. Re 'Luminescence dating of Kfeldspar from sediments: a protocol without anomalous fading correction' by Bo Li and Sheng-Hua Li. Quaternary Geochronology, this issue. 


\section{Figure caption:}

Fig. 1: Comparison of the expected doses (see Table 1 for details) and the equivalent doses obtained using different protocols in Table 2. The MET-pIRIR (250) data shows the results obtained from the $250^{\circ} \mathrm{C}$ MET-pIRIR signals. See $\mathrm{Li}$ and $\mathrm{Li}$ (submitted) for the results obtained from the other MET-pIRIR temperatures. The straight line is the 1:1 line. 


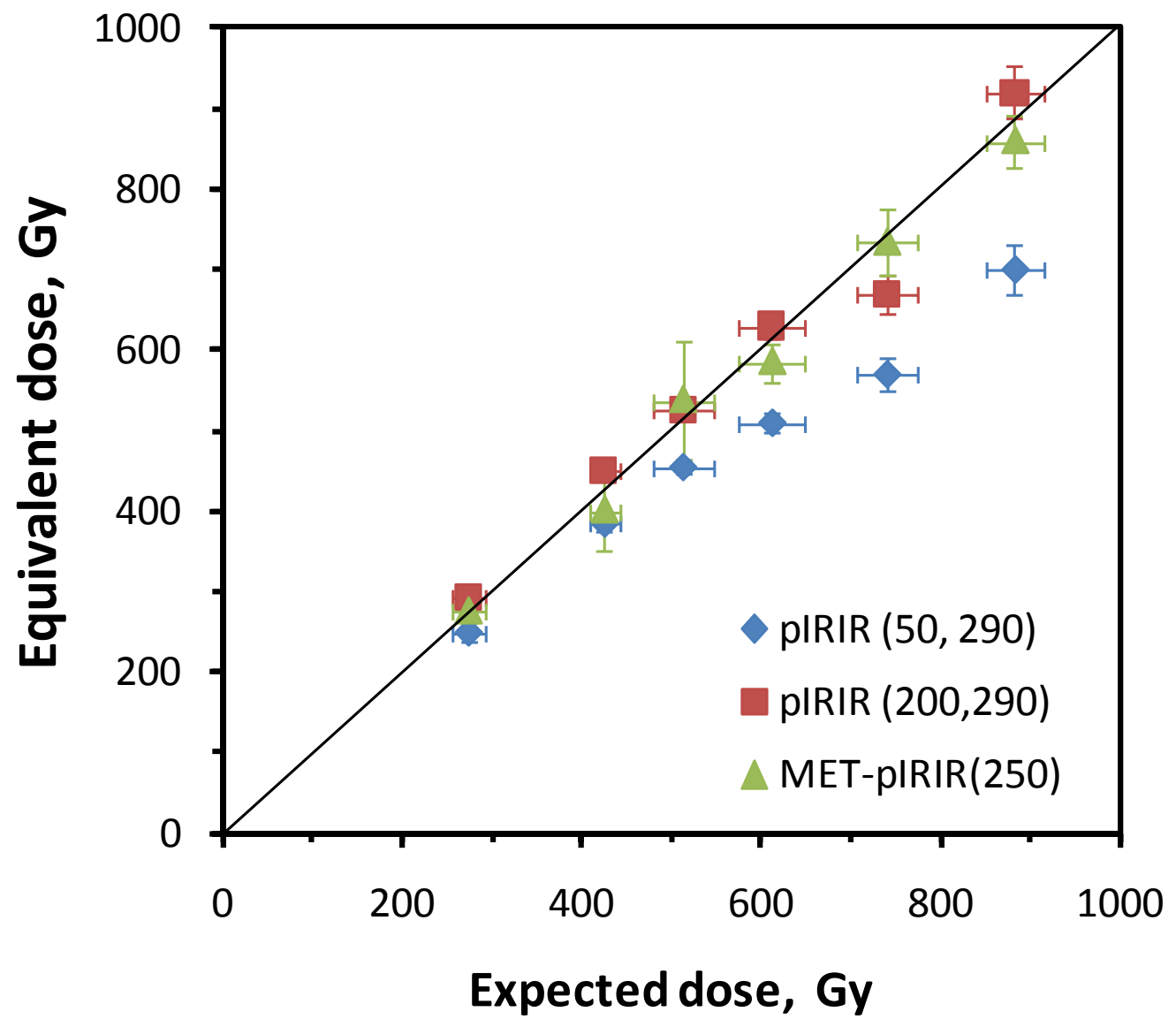

Figure 1 
Table 1: Summary of the samples, depth, expected ages and doses, dose rate and equivalent doses.

\begin{tabular}{|l|c|c|c|c|c|c|c|}
\hline Sample & Depth (m) & $\begin{array}{c}\text { Expected age } \\
(\mathrm{ka})^{\mathrm{a}}\end{array}$ & $\begin{array}{c}\text { Dose rate } \\
(\mathrm{Gy} / \mathrm{ka})\end{array}$ & $\begin{array}{c}\text { Expected dose } \\
(\mathrm{Gy}){ }^{\mathrm{b}}\end{array}$ & \multicolumn{3}{|c|}{ Equivalent dose (Gy) } \\
\cline { 5 - 8 } & & & & & & & \multicolumn{3}{|c|}{ MET-pIRIR (250) } & pIRIR(50, 290) & pIRIR(200, 290) \\
\hline LC-096 & 9.6 & $75 \pm 5$ & $3.6 \pm 0.1$ & $273 \pm 18$ & $275 \pm 13$ & $250 \pm 11$ & $293 \pm 11$ \\
LC-120 & 12.0 & $124 \pm 5$ & $3.5 \pm 0.1$ & $425 \pm 17$ & $401 \pm 49$ & $385 \pm 11$ & $450 \pm 8$ \\
LC-150 & 15.0 & $152 \pm 10$ & $3.4 \pm 0.1$ & $512 \pm 34$ & $537 \pm 75$ & $455 \pm 9$ & $525 \pm 5$ \\
LC-170 & 17.0 & $170 \pm 10$ & $3.6 \pm 0.1$ & $612 \pm 36$ & $585 \pm 24$ & $510 \pm 13$ & $630 \pm 15$ \\
LC-205 & 20.5 & $214 \pm 10$ & $3.5 \pm 0.1$ & $740 \pm 35$ & $733 \pm 41$ & $570 \pm 20$ & $670 \pm 23$ \\
LC-230 & 23.0 & $263 \pm 10$ & $3.4 \pm 0.1$ & $883 \pm 34$ & $859 \pm 34$ & $700 \pm 31$ & $920 \pm 33$ \\
\hline
\end{tabular}

Note: ${ }^{\text {a }}$ The expected ages are the stratigraphic ages estimated from linear interpolation of their stratigraphic positions into the corresponding loess/paleosol boundary ages in which the samples were embedded (Ding et al. 2002). See Li and Li (submitted) for a detailed description of the samples and their stratigraphic ages.

${ }^{\mathrm{b}}$ The expected doses were calculated using the expected ages multiplied by the dose rate for each sample. 
Table 2: The procedures of MET-pIRIR, pIRIR(50, 290) and pIRIR $(200,290)$ measurement protocols.

\begin{tabular}{|ccc|}
\hline \multicolumn{4}{|c|}{ MET-pIRIR protocol } \\
\hline Step & Treatment & Observed \\
\hline 1 & Give regenerative dose, $\mathrm{D}_{\mathrm{i}}{ }^{\mathrm{a}}$ \\
2 & Preheat at $320^{\circ} \mathrm{C}$ for $60 \mathrm{~s}$ \\
3 & IRSL measurement at $50^{\circ} \mathrm{C}$ for $100 \mathrm{~s}$ & $\mathrm{~L}_{\mathrm{x}(50)}$ \\
4 & IRSL measurement at $100^{\circ} \mathrm{C}$ for $100 \mathrm{~s}$ & $\mathrm{~L}_{\mathrm{x}(100)}$ \\
5 & IRSL measurement at $150^{\circ} \mathrm{C}$ for $100 \mathrm{~s}$ & $\mathrm{~L}_{\mathrm{x}(150)}$ \\
6 & IRSL measurement at $200^{\circ} \mathrm{C}$ for $100 \mathrm{~s}$ & $\mathrm{~L}_{\mathrm{x}(200)}$ \\
7 & IRSL measurement at $250^{\circ} \mathrm{C}$ for $100 \mathrm{~s}$ & $\mathrm{~L}_{\mathrm{x}(250)}$ \\
8 & IRSL measurement at $300^{\circ} \mathrm{C}$ for $100 \mathrm{~s}$ & $\mathrm{~L}_{\mathrm{x}(300)}$ \\
9 & Give test dose, $\mathrm{D}_{\mathrm{t}}$ & \\
10 & Preheat at $320^{\circ} \mathrm{C}$ for $60 \mathrm{~s}$ & \\
11 & IRSL measurement at $50^{\circ} \mathrm{C}$ for $100 \mathrm{~s}$ & $\mathrm{~T}_{\mathrm{x}(50)}$ \\
12 & IRSL measurement at $100^{\circ} \mathrm{C}$ for $100 \mathrm{~s}$ & $\mathrm{~T}_{\mathrm{x}(100)}$ \\
13 & IRSL measurement at $150^{\circ} \mathrm{C}$ for $100 \mathrm{~s}$ & $\mathrm{~T}_{\mathrm{x}(150)}$ \\
14 & IRSL measurement at $200^{\circ} \mathrm{C}$ for $100 \mathrm{~s}$ & $\mathrm{~T}_{\mathrm{x}(200)}$ \\
15 & IRSL measurement at $250^{\circ} \mathrm{C}$ for $100 \mathrm{~s}$ & $\mathrm{~T}_{\mathrm{x}(250)}$ \\
16 & IRSL measurement at $300^{\circ} \mathrm{C}$ for $100 \mathrm{~s}$ & $\mathrm{~T}_{\mathrm{x}(300)}$ \\
17 & IR bleaching at $325^{\circ} \mathrm{C}$ for $100 \mathrm{~s}$ & \\
18 & Return to step 1 & \\
\hline
\end{tabular}

\begin{tabular}{|ccc|}
\hline \multicolumn{3}{|c|}{ pIRIR(50,290) protocol } \\
\hline Step & Treatment & Observed \\
\hline 1 & Give regenerative dose, $\mathrm{D}_{\mathrm{i}}{ }^{\text {a }}$ \\
2 & Preheat at $320^{\circ} \mathrm{C}$ for $60 \mathrm{~s}$ \\
3 & IRSL measurement at $50^{\circ} \mathrm{C}$ for $200 \mathrm{~s}$ & $\mathrm{~L}_{\mathrm{x}(50)}$ \\
4 & IRSL measurement at $290^{\circ} \mathrm{C}$ for $200 \mathrm{~s}$ & $\mathrm{~L}_{\mathrm{x}(290)}$ \\
5 & Give test dose, $\mathrm{D}_{\mathrm{t}}$ & \\
6 & Preheat at $320^{\circ} \mathrm{C}$ for $60 \mathrm{~s}$ & \\
7 & IRSL measurement at $50^{\circ} \mathrm{C}$ for $200 \mathrm{~s}$ & $\mathrm{~T}_{\mathrm{x}(50)}$ \\
8 & IRSL measurement at $290^{\circ} \mathrm{C}$ for $200 \mathrm{~s}$ & $\mathrm{~T}_{\mathrm{x}(290)}$ \\
9 & IR bleaching at $325^{\circ} \mathrm{C}$ for $40 \mathrm{~s}$ & \\
10 & Return to step 1 & \\
\hline
\end{tabular}

\begin{tabular}{|ccc|}
\hline \multicolumn{3}{|c|}{ pIRIR(200,290) protocol } \\
\hline Step & Treatment & Observed \\
\hline 1 & Give regenerative dose, $\mathrm{D}_{\mathrm{i}}{ }^{\text {a }}$ \\
2 & Preheat at $320^{\circ} \mathrm{C}$ for $60 \mathrm{~s}$ & \\
3 & IRSL measurement at $200^{\circ} \mathrm{C}$ for $200 \mathrm{~s}$ & $\mathrm{~L}_{\mathrm{x}(50)}$ \\
4 & IRSL measurement at $290^{\circ} \mathrm{C}$ for $200 \mathrm{~s}$ & $\mathrm{~L}_{\mathrm{x}(290)}$ \\
5 & Give test dose, $\mathrm{D}_{\mathrm{t}}$ & \\
6 & Preheat at $320^{\circ} \mathrm{C}$ for $60 \mathrm{~s}$ & \\
7 & IRSL measurement at $200^{\circ} \mathrm{C}$ for $200 \mathrm{~s}$ & $\mathrm{~T}_{\mathrm{x}(50)}$ \\
8 & IRSL measurement at $290^{\circ} \mathrm{C}$ for $200 \mathrm{~s}$ & $\mathrm{~T}_{\mathrm{x}(290)}$ \\
9 & IR bleaching at $325^{\circ} \mathrm{C}$ for $40 \mathrm{~s}$ & \\
10 & Return to step 1 & \\
\hline
\end{tabular}

${ }^{a}$ For the 'natural' sample, $\mathrm{i}=0$ and $\mathrm{D}_{0}=0$. The whole sequence is repeated for several regenerative doses including a zero dose and a repeat dose. 